\title{
Failures to disagree' is essential for environmental science to effectively influence policy development.
}

\author{
Jon Norberg ${ }^{1}$, Thorsten Blenckner ${ }^{1}$, Sarah Cornell ${ }^{1}$, Owen Petchey ${ }^{2}$, and Helmut \\ Hillebrand $^{3}$ \\ ${ }^{1}$ Stockholm University \\ ${ }^{2}$ University of Zurich \\ ${ }^{3}$ University of Oldenburg
}

September 25, 2021

\begin{abstract}
While environmental science, and ecology in particular, is working to provide better understanding to base sustainable decisions on, the way scientific understanding is developed can at times be detrimental to this cause. Locked-in debates are often unnecessarily polarized and can compromise any common goals of the opposing camps. The present paper is inspired by a resolved debate from an unrelated field of psychology where Nobel laureate David Kahneman and Garry Klein turned what seemed to be a locked-in debate into a constructive process for their fields. The present paper is also motivated by previous discourses regarding the role of thresholds in natural systems for management and governance, but its scope of analysis targets the scientific process within complex social-ecological systems in general. We identified five features of environmental science that appear to predispose for locked-in debates: 1) The strongly context dependent behaviour of ecological systems. 2) The dominant role of single hypothesis testing. 3) The high prominence given to theory demonstration compared investigation. 4) The effect of urgent demands to inform and steer policy. This fertile ground is further cultivated by human psychological aspects as well as the structure of funding and publication systems.
\end{abstract}

\section{Hosted file}

NorbergEtAl.pdf available at https://authorea.com/users/437235/articles/539012-failuresto-disagree-is-essential-for-environmental-science-to-effectively-influence-policydevelopment

\section{Hosted file}

Manuscript table.pdf available at https://authorea.com/users/437235/articles/539012-failuresto-disagree-is-essential-for-environmental-science-to-effectively-influence-policydevelopment 